Volume 2, Issue 2, April-June 2017, Pages: 184, DOI: http://dx.doi.org/10.19082/ah184

\title{
IRAN FAMILIAL BREAST CANCER REGISTRY (IRFBCR)-MISSION AND STRUCTURE
}

\author{
Reza Shirkoohi ${ }^{1,2}$, Keivan Majidzadeh-A ${ }^{3}$, Elmira Ebrahimi $^{1}$, Ali Rafei $^{4}$, Kazem $_{\text {Zendehdel }}{ }^{1,2}$ \\ 1: Cancer Research Center, Cancer Institute of Iran, Tehran University of Medical Sciences, Tehran, Iran \\ 2: Cancer Biology Research Center, Cancer Institute, Imam Khomeini Hospital Complex, Tehran, Iran \\ 3: Breast Cancer Research Center (BCRC), ACECR, Tehran, Iran \\ 4: Institute for Social Research, University of Michigan, Michigan, USA
}

Correspondence:

Tel: +982166914545, Email: rshirkoohi@tums.ac.ir

TYPE OF ARTICLE: CONFERENCE ABSTRACT

\begin{abstract}
Introduction: Iran Familial Breast Cancer Registry (IRFBCR) was established by the Cancer Research Center and Breast Cancer Research Center (BCRC), as the members of the National Cancer Research Network, in 2016. The main purpose of IRFBCR registry is to play a part in patient care by systematic collection, storage, analysis and interpretation of data of patients with familial breast cancer, and to further develop prevention and treatment strategies in regards to familial breast cancer.

Methods: Based on the latest international guidelines, different questionnaires have been developed to collect demographics, height and weight, ethnicity, personal history of cancer, medical and surgical history, radiation exposure, smoking and alcohol consumption, menstrual and pregnancy history, breastfeeding, hormone use, and physical activity as well as the patient's tumor tissue characteristics and the treatment that each patient has received in regards to her/his disease. In addition, an informatics center is also being considered for core data collation, management and distribution. Bio-banking of each patient's bio-specimen is also being considered in this project.

Results: So far, 20 patients have been recruited and their blood and DNA samples have been saved as a bio-specimen repository.

Conclusion: Based on this resource, not only the prevalence of the disease in patients with familial breast cancer in this country can be estimated, but also, it will be a good source for further studies to investigate factors of efficient causes, whether genetic or environmental, contributing in the incidence of familial breast cancer.
\end{abstract}

KEYWORDS: Breast cancer, Registry, Biobank

\footnotetext{
Abstracts of First National Congress of Medical Informatics, Mashhad, Iran, February 2017

(C) 2017 The Authors. This is an open access article under the terms of the Creative Commons Attribution-NonCommercialNoDerivs License, which permits use and distribution in any medium, provided the original work is properly cited, the use is non-commercial and no modifications or adaptations are made.
} 